\title{
Psychometric properties of the Multi-group Ethnic Identity Measure (MEIM) in a sample of Iranian young adults
}

\author{
Mojtaba Habibi ${ }^{1,2}$, Maede Sadat Etesami ${ }^{\text {Corresp., 1,3,4 }}$, Mohammadali Taghizadeh $^{5}$, Faezeh Sadat Akrami ${ }^{6}$, Danilo \\ Garcia ${ }^{\text {Corresp. 7, 8, 9, 10,11 }}$ \\ 1 Health promotion Research Center, Iran University of Medical Sciences, Tehran, Iran \\ 2 Department of Health Psychology, , School of Behavioral Sciences and Mental Health (Tehran Institute of Psychiatry), Iran University of Medical Sciences, \\ Tehran, Iran \\ 3 Department of Clinical Psychology, University of Tehran, Tehran, Iran \\ 4 Iranian Research Center for HIV/AIDS (IRCHA), Department of Infectious Diseases, Imam Khomeini Hospital Complex, Tehran, Iran \\ 5 Department of Counseling, Shaheed Beheshti University, Tehran, Iran \\ 6 Department of Clinical Psychology, School of Humanities and Social sciences, Islamic Azad University, Science and Research Branch, Tehran, Iran \\ 7 Department of Behavioral Sciences and Learning, Linköping University, Linköping, Sweden \\ 8 Center for Ethics, Law and Mental Health (CELAM), University of Gothenburg, Gothenburg, Sweden \\ 9 Promotion of Health and Innovation (PHI) Lab, Network for Well-Being, Karlskrona, Sweden \\ 10 Department of Psychology, University of Gothenburg, Gothenburg, Sweden \\ 11 Blekinge Centre of Competence, Region Blekinge, Karlskrona, Sweden \\ Corresponding Authors: Maede Sadat Etesami, Danilo Garcia \\ Email address: etesami.m@iums.ac.ir, danilo.garcia@icloud.com
}

Background. This study examines the factor structure, reliability and test-retest validity of the 12-item Iranian version of the Multigroup Ethnic Identity Measure (MEIM). Additionally, the MEIM's concurrent validity was tested by investigating the association between ethnic identity and subjective well-being.

Method. The scale was translated into Persian language and was administered to 426 students (193 female) at a major public university in Tehran along with the Positive Affect Negative Affect Schedule, and the Satisfaction with Life Scale.

Results. The confirmatory factor analysis supported the two-factor first-order commitment, and exploration - consisting of 12 items, and the second-order unidimensional factor structure of general ethnic identity. Moreover, we found evidence for good internal consistency, test re-test reliability, and concurrent validity.

Conclusion. The MEIM Persian version was found to be a valid and reliable measure to examine ethnic identity in this Iranian student population, for both males and females. These results support the utility of the Persian version of the MEIM for its use in middle-eastern contexts. Key words: ethnic identity, youth, measurement model, Multi-group Ethnic Identity Measure. 


\section{Psychometric Properties of the Multi-group Ethnic Identity Measure (MEIM) in a Sample of Iranian Young Adults} Mojtaba Habibi ${ }^{1,2}$, Maede Sadat Etesami ${ }^{\text {Corresp.2, 3,4 }}$, MohammadAli Taghizadeh $^{5}$, Faezeh Sadat Akrami ${ }^{6}$, Danilo Garcia ${ }^{\text {Corresp. 7, 8, 9, 10,11 }}$

${ }^{1}$ Department of Health Psychology, School of Behavioral Sciences and Mental Health (Tehran Institute of Psychiatry), Iran University of Medical Sciences, Tehran, Iran

2 Health promotion Research Center, Iran University of Medical Sciences, Tehran, Iran

${ }^{3}$ Department of Clinical Psychology, University of Tehran, Tehran, Iran

${ }^{4}$ Iranian Research Center for HIV/AIDS (IRCHA), Department of Infectious Diseases, Imam Khomeini Hospital Complex, Tehran, Iran

${ }^{5}$ Department of Counseling, Shahid Beheshti University, Tehran, Iran

${ }^{6}$ Department of Clinical Psychology, School of Humanities and Social sciences, Islamic Azad University, Science and Research Branch, Tehran, Iran

${ }^{7}$ Department of Behavioral Sciences and Learning, Linköping University, Linköping, Sweden

${ }^{8}$ Center for Ethics, Law and Mental Health (CELAM), University of Gothenburg, Gothenburg, Sweden

${ }^{9}$ Promotion of Health and Innovation (PHI) Lab, Network for Well-Being, Karlskrona, Sweden

10 Department of Psychology, University of Gothenburg, Gothenburg, Sweden

11 Blekinge Centre of Competence, Region Blekinge, Karlskrona, Sweden

* Proofs and Correspondence:

Maede Sadat Etesami, Health promotion research

center, University of Medical Sciences, Tehran, Iran

P.O. Box: 1445613111

Zip Code: $14565 / 441$

Tel: $+98-912-7791633$

Fax: +98-21-66506853

Email: msetesamy@gmail.com;

Etesami.m@iums.ac.ir 
36

38

39

40

41

42

Danilo Garcia, Network for Well-Being, Blekinge, Nättraby, Sweden

Adress: Sieslättsvägen 18

Zip Code: 37332

Tel: +46733105153

Email: danilo.garcia@icloud.com

\section{ABSTRACT}

Background. This study examines the factor structure, reliability and test-retest validity of the 12-item Persian version of the Multigroup Ethnic Identity Measure (MEIM) in a sample of young Iranian adults. Additionally, the MEIM's concurrent validity is tested by investigating its association with subjective well-being.

Method. The scale was translated into Persian language and was administered to 426 students (193 females) at a major public university in Tehran along with the subjective wellbeing measures: the Positive Affect Negative Affect Schedule, and the Satisfaction with Life Scale.

Results. The confirmatory factor analysis supported the two-factor first-order commitment, and exploration - consisting of 12 items. Moreover, we found evidence for good internal consistency, test re-test reliability, and concurrent validity for the test.

Moreover, the MEIM and its subscales showed a positive relationship with positive affect and Life satisfaction and a negative relationship with negative affect. However, the total score of the MEIM was weakly related to the subjective well-being measures. 
58

59

60

61

62

63

64

65

66

67

68

Conclusion. The 12-item MEIM Persian version was found to be a valid and reliable measure to examine ethnic identity in this Iranian student population, for both males and females. These results support the suitability of this measure for use in middle-eastern contexts. Key words: ethnic identity, youth, measurement model, Multi-group Ethnic Identity Measure. Psychometric Properties of the Multi-group Ethnic Identity Measure (MEIM) in a Sample of Iranian Young Adults

\section{INTRODUCTION}

Ethnic identity is a multidimensional and ever-evolving phenomena that has been defined in various ways. Tajfel (1981), for example, defined ethnic identity as part of one's individuality that comes from the understanding of one's membership in an ethnic group with particular values and emotions. Similarly, Helms (2007) defined it as belonging to an ethnic group that has specific heritage, values and characteristics (Phinney \& Ong, 2007). Regardless of the definition, ethnic identity is a component of the question: "who am I?", and therefore a powerful factor in the development and preservation of ethnic groups and their social bonds. At the same time, its formation is affected by socialization processes and individuals' internal dynamics within an ethnic group (Bernal \& Knight, 1993).

The psychological study of ethnic identity formation has its foundation in the ego identity model of Erik Erikson (1968). According to Erikson, one's identity begins developing in childhood, through a process of "reflection and observation", it becomes particularly prominent during adolescence and early adulthood but may continue through the later stages of adulthood and usually leads to a resolution or an achieved identity (Erikson, 1968, p. 22). Individuals who fail a resolution may either 
80

81

82

withdraw further into social isolation or become lost in the crowd. The empirical study of personal identity was later advanced by James Marcia (1980), who theorized identity development as involving two main processes, exploration of identity issues and commitment to significant and related identity domains. Inspired by Erikson's and Marcia's research, developmental psychologist Jean S. Phinney has suggested a three-stage model for ethnic identity development. This model serves as the basis for the present study.

Phinney (2000) defines identity as a multidimensional and ever-changing sense of the self in relation to an ethnic group, which is in fact a subgroup within a larger context including culture, race, religion, language, kinship and or place of origin. This sense of the self is not fixed and can change over time and/or different situations (Herrington, Smith, Feinauer, \& Griner, 2016). Phinney (1992) holds that with the facilitation of parents and society, youngsters belonging to different ethnic groups have the possibility to develop ethnic identity and that this development is positively related with psychological competence. In sum, Phinney's (1993)

Developmental Model of Identity applies to all ethnic groups, is based on Marcia's conceptualization of Erikson's theory of identity, and focuses on identity development during adolescence. In subsequent studies, Phinney and others have found that the process of acquiring ethnic identity involves exploration and then affirmation of an individual's identity (Vedder \& Phinney, 2014). Thus, among young adults, if individuals complete the developmental stages of ethnic identity and affirm their ethnic identity, they grow in selfacceptance (Ivory, 2002). Importantly, self-acceptance is an important factor in one's 
101 psychological health and well-being (Bernard, Vernon, Terjesen, \& Kurasaki, 2013; Garcia, Al

102 Nima, \& Kjell, 2014; Maclnnes, 2006).

103 In this context, individuals with a highly developed ethnic identity explore their

104 commitments towards their ethnic group (Ontai-Grzebik \& Raffaelli, 2004), therefore, they

105 recognize their group members, make positive evaluations of their group, have good feelings

106 about being members of the group and perform certain ethnic rituals. On the other hand,

107 individuals with a poorly developed ethnic identity pay little attention to their group members,

108 make negative evaluations of the group to which they belong, do not have a good feeling about

109 being members of the group and do not perform customary commitments to the group

110 (Phinney, 1991). Consequentially, ethnic identity and subjective well-being have been found to

111 have a positive relationship in different ethnic populations (Herrington et al., 2016; Syed et al,

112 2013; Smith \& Silva, 2011; Krieger, 2010; Iwamoto \& Liu, 2010; Umana-Taylor, 2004).

\section{Ethnic Identity and Subjective Well-being}

114 Subjective well-being involves a positive feeling and a general sense of satisfaction with

115 different areas of life (Myers \& Diner, 1995). According to Pavot and Diner (2004), subjective

116 well-being consists of two distinct, but related components: an emotional component (i.e.,

117 positive and negative affect) and a cognitive component (i.e., satisfaction with life). Positive

118 affect reflects the occurrence of positive emotional states such as joy, interest and happiness.

119 In contrast, negative affect involves negative emotional states such as anger, fear, sadness and

120 guilt (Pavot, 2004). The cognitive component of subjective well-being refers to an assessment

121 of the quality of different aspects of one's life and a general feeling of satisfaction with life

122 (Gilman, Huebner \& Laughlin, 2000). Life satisfaction, positive affect, and negative affect are 
123 considered as independent phenomena (Lucas, Diner \& Sue 1996) and are therefore often

124 evaluated individually rather than as an integrated entity (for other perspectives see Nima,

125 Cloninger, Luchesse, Sikström \& Garcia, 2020; Nima, Cloninger, Persson, Sikström \& Garcia,

126 2020; Garcia, Nima, Granjard \& Cloninger, 2020).

127 Several studies have demonstrated a significant positive correlation between ethnic

128 identity and subjective well-being (e.g. Ali, 2006; Diaz \& Bui, 2017; Oliveira, Pankalla, \&

129 Cabecinhas, 2012; Syed et al., 2013; Yoo \& Lee, 2005). There have also been studies indicating

130 that strong ethnic identity can reduce negative emotions (Williams, Chapman, Wong \&

131 Turkheimer, 2012; Yip \& Fuligni, 2002; Roberts et al, 1999) and that successful ethnic identity

132 formation can predict an overall sense of well-being (Vleioras \& Bosma, 2005; Waterman, 2007;

133 Hejazi, Shahraray, Farsinejad \& Asgary, 2008). In addition, a significant relationship between

134 identity development and well-being has been demonstrated by few studies conducted in Iran

135 (Musavi, Rushan \& Akbari, 2010; Alijani, 2006; Ghazanfari, 2003). Nevertheless, as most studies

136 in this field have been conducted in western cultural contexts, the generalizability of these

137 findings to Iran is limited, since Iran is an Islamic Middle Eastern society with a multiethnic

138 culture. Such culture, has for example, a different approach to gender issues.

139 Ethnic Identity and Gender

140 Research related to ethnic identity and gender has shown mixed results (e.g., Kazarian \&

141 Boyadjian, 2008; Ontai-Grzebik \& Raffaelli, 2004; Phinney, Cantu \& Kurtz, 1997; Swenson \&

142 Prelow, 2005; Yin lum, 2008). For instance, in a study by Dandy and colleagues (2008), no

143 significant gender differences were observed in identity affirmation, but females were more

144 inclined to interact and socialize with other ethnic groups. Other studies, however, indicate 
145 higher levels of ethnic identity among males compared to females (e.g., Chau Vo, 2008; Go \&

146 Le, 2005; Mossakowski, K. N. 2018). Yet other studies show that females score higher than

147 males in ethnic identity (e.g., Cislo, 2008; Creagh-kaiser, 2003; Sobansky et al., 2010).

148 That being said, at least theoretically, the association between ethnic identity and

149 psychological outcomes, such as life satisfaction and affect, can be mediated by gender. For

150 example, Cross and Madson (1997) suggested that since women are more relationship-

151 oriented, their life satisfaction may be positively affected by the sense of belongingness to their

152 ethnic group. Other studies (e.g., Navarrete, McDonald, Molina, \& Sidanius, 2010) have

153 suggested that since men are more commonly the target of racial discrimination, ethnic

154 identity has a larger impact on them compared to its impact on women (Yap, Settles \& Pratt-

155 Hyatt, 2011). Hence, despite the mixed results regarding gender, besides the relationship

156 between ethnic identity and subjective well-being, we also investigate gender differences in

157 ethnic identity using one of the most prominent ethnic identity measures.

\section{The Multigroup Ethnic Identity Measure (MEIM)}

159 Several models and measures for the assessment of ethnic identity have been proposed. Most

160 of which are based on the works of Erikson, Tajfel, and Phinney (see Umana-Taylor, 2004).

161 Many of the earlier measures were designed for specific ethnic groups, thus, making cross-

162 ethnic comparisons impossible. In order to measure ethnic identity across cultures, Phinney

163 (1992) introduced a 20-item ethnic identity measure (i.e., MEIM-O) that included five items to

164 measure Affirmation and Belonging, seven items to measure Ethnic Identity Achievement, two

165 items for Ethnic Behaviors, and six additional items to assess Other Group Orientation (OGO).

166 Phinney (1992) considered the two factors, Ethnic Identity and OGO, for MEIM-O based on an 
167 exploratory factor analysis done on data collected among American students from different

168 ethnic groups. Later on, in 1999, the original MEIM was revised by Roberts, Phinney, Masse, 169 Chen, Roberts, and Romero, who carried out an exploratory factor analysis on 14 MEIM items

170 (not including the six OGO items). They administered the test to 5,423 young adolescents (sixth

171 to eighth graders) from a variety of ethnicities including African American $(n=1,237)$; Central

172 American $(n=253)$; Chinese American $(n=177)$; European American $(n=755)$; Indian American

173 ( $n=188)$; Mexican American $(n=755)$; Pakistani American $(n=155)$; Vietnamese American $(n=$

174 304); Pacific Islander $(n=101)$; and mixed ancestry $(n=342)$. The results showed that the two

175 items assessing Ethnic Behaviors (i.e., being active in ethnic organizations and participating in

176 cultural practices) were misunderstood among younger adolescents and were therefore

177 removed. Thus, arriving to the version of the MEIM used in the present study; which consists of

17812 items and two factors, namely exploration and commitment. More specifically, of the 12

179 remaining items, five items represent exploration and seven items represent commitment

180 (Herrington et al., 2016) ${ }^{1}$.

\section{The MEIM among Diverse Populations}

The MEIM in all its multiple versions (including MEIM-O, three-factor 14-item, two-factor 12-

item and two-factor 6-item), has been used in dozens of studies and has consistently shown

good reliability, typically with alphas above .80 across a wide range of ethnic groups and ages.

Table 1 shows the reliabilities of the two-factor 12 -item version of the MEIM in several studies

${ }^{1}$ There is also a shorter version of MEIM developed by Phinney and Ong (2007), the Multigroup Ethnic Identity Measure-Revised (MEIM-R) which consists of six items, three of which are related to Exploration and three items to Commitment. These six items were all derived from the 12-item MEIM except for one new item for Exploration: "I have often done things that will help me understand my ethnic background better". 
186

187

188

189

190

191

192

193

194

195

196

197

198

199

200

201

202

203

204

205

206

207

across different populations. As shown by Roberts and colleagues' work (1999), including a

factor analysis of a large sample of adolescents, it seems that the measure can be considered as comprising of two factors: 1) ethnic identity search (a developmental and cognitive component) and 2) affirmation, belonging, and commitment (an affective component; Pegg et al., 2005). To the best of our knowledge, despite the existence of identity studies among different Iranian ethnicities, no published study has tested the factorial validity of the 12 -item version of MEIM in a sample drawn from a Middle Eastern population.

\section{Prior Research on Ethnic Identity in Young Iranian Adults}

For instance, Moghaddas Jafari, Sheikhavandi \& Sharif Pour (2008) studied 347 Kurdish university students of Saqqez Payam-e-Noor University, a Kurdish university located in the west of Iran. They found that Kurdish students were to a large extent committed to all components of ethnic and national identity. They also showed perceived social inequality was the most important factor explaining and predicting commitment to ethnic and national identity. It is worth mentioning that Iranian ethnic groups reside mostly in the borders of Iran, but also beyond the borders. For example, Kurds partly dwell in Iran and partly in neighboring countries including Turkey and Iraq. Therefore, it has long been a concern of the Iranian central government to maintain the unity of the country in order to strengthen the central power and national security. In this regard, over different eras, political leaders have tried to promote the common aspects of the Iranian culture as opposed to different cultures of ethnic groups within the country. Quite often this has led to the negligence or even suppression of ethnic communities (Amanolahi, 2005; Saleh, 2013). The national media in Iran, for instance, mostly promulgates the Persian and Shi'i values and culture while the global media emphasizes cultural 
208 integration and globalization (Gulyas, 2017; Saleh, 2013). Indeed, modernization and

209 globalization tendencies have, in certain ways, notably blurred the distinctive characteristics of

210 different ethnic groups. Studies show that, although in recent years there have been several

211 measures taken in Iran to appreciate ethnic differences, for example by teaching Kurdish and

212 Turkish language courses at certain universities, there is still a long way to go before

213 satisfactory condition are created, where all Iranian ethnicities and sub-cultures are respected

214 and appreciated (Gulyas, 2017; Saleh, 2013).

Nevertheless, Hajiyani (2008) demonstrated that both ethnic and national identity are

strong and prominent among the six main Iranian minorities including Turks, Kurds, Lurs,

Balochs, Arabs and Turkmen. They also found a significant positive relationship between the sociocultural dimensions of ethnic identity and the cultural and somewhat social dimensions of

national identity. Despite the importance of these studies, a major problem is that a majority, if

not all, have not used standard models and measures when assessing ethnic identity. This

makes comparisons across and within cultures impossible. Standard measures for ethnic

identity assessment, such as the MEIM, are under attention in other countries, making research

findings comparable.

The Present Study

It is important to notice that Iran is a very diverse country with seven main distinctive

227 (10\%), Lurs (6\%), Arabs (2\%), Balochs (2\%), and Turkmens and Turkic tribes (2\%). In addition,

228 there is very small number of Armenians, Assyrians, and Georgians (World population review,

229 2019). All these ethnicities are referred to as "Iranian", since they are basically from Iran and 
over the centuries, they have inhabited the Iranian land. At the same time, due to

231

modernization, industrialization, and other economic and political issues, the country has experienced an increase in internal migration patterns, which have in turn resulted in cities becoming more and more multi-ethnic over the last few decades.

Despite the fact that the MEIM has been extensively used in research around the world, to the best of our knowledge, no psychometric research has been done on the 12-item MEIM in the Iranian young adult population. Additionally, the 12-item MEIM has not been used for assessing ethnic identity in different Iranian ethnic groups. Therefore, this study aimed to confirm the two-factor structure of the Persian version of the 12-item MEIM in a sample of young Iranian adults using confirmatory factor analysis (CFA). In addition, we examined gender differences, test-retest validity, and the reliability of the MEIM. In other words, this research explored the cross-national generalizability of the MEIM's factor structure and also provided an additional test of its construct validity and reliability. Parallel to these aims, we also investigated the association between ethnic identity and subjective well-being (positive affect, negative affect, and life satisfaction). In short, the present paper had three main objectives: (1)

To evaluate the factorial validity and test-retest reliability of the MEIM among a sample of young Iranian students, (2) To examine ethnic identity, as measured by the MEIM, in relation to subjective well-being in order to test the concurrent validity of the MEIM (3), and to examine possible gender differences in ethnic identity. Regarding subjective well-being, we expected that (a) ethnic identity will be positively associated with positive affect, (b) negatively associated with negative affect, and (c) and positively related to life satisfaction. 


\section{Participants}

253 Participants were considered eligible if they were within 17 to 40 years of age, had at least

254 completed one semester of university studies, and provided written informed consent for

255 participation in the study. Those who reported psychiatric disorders, organic brain disorder,

256 and/or drug dependence were excluded from the study. Sample size estimation was based on

257 the rule of thumb suggested by Bentler and Chou (1987). A total of 500 undergraduate students

258 volunteered to participate in the normative sample, but $50(10 \%)$ students were excluded

259 because they had responded to less than $90 \%$ of the questions. Out of the remaining 450

260 participants, 24 were withdrawn from the study due to noncompliance. Hence, the final sample

261 included 426 students (91.8\% of whom reported being single and $54.7 \%$ were males). The

262 percentages of participants from different ethnic groups were as follows: $33.1 \%$ Turks,

$26328.9 \%$ Farses, $21.4 \%$ Lors, and $16.7 \%$ Kurds. The average age was 21.98 years and ranged from

26418 to 31 years. The students were $60.3 \%$ undergraduates and $39.7 \%$ graduates and were from

265 three faculties: Social Sciences (45.1\%), Foundational Sciences (33.3\%) and Engineering (21.6\%).

266 Most of the participants lived in dormitory (70.7\%) and the remaining lived with their parents

267 or spouses. All participants were offered the option to take the MEIM on one or two occasions.

268 Those who wanted to take the test twice were part of the test-retest subsample and took the

269 test for the second time after a four-week interval. The test-retest sub-sample $(n=50 ; 25$

270 males) had a mean age of 23 years (age range $18-30$ years). 
271

272

273

274

275

276

277

278

279

280

281

282

283

\section{Measures}

Multigroup Ethnic Identity Measure (MEIM). The MEIM (Phinney, 1998) contains 12 items that can be divided into two subscales: 1) exploration and 2) commitment. The items are rated on a four-point Likert-type scale that ranges from 1 indicating "strongly disagree" to 4 indicating "strongly agree".

Positive and Negative Affect Schedule (PANAS). A self-report assessment of the affective component of subjective well-being in which participants are instructed to rate to what extent they generally have experienced 20 different emotions (10 positive emotions and 10 negative emotions) for the last four weeks, using a 5 -point Likert scale $(1=$ very slightly, $5=$ extremely) (Watson, Clark \& Tellegren, 1988). The 10-item positive affect scale includes adjectives such as strong, proud, and interested. The 10-item negative affect scale includes adjectives such as afraid, ashamed, and nervous. The PANAS is usually used to operationalize the emotional component of subjective well-being and has excellent internal consistency ranging from .84 to .90 as indicated by Conbrach's alpha coefficients (Cloninger \& Garcia, 2015; see also Yoo \& Lee, 2005; Vera et al., 2008). The internal reliability in the present study for the positive affect scale was .80 and that for the negative affect scale was .87 .

Satisfaction with Life Scale (SWLS). This scale is a self-report measure that assesses the cognitive component of subjective well-being and consists of 5 items (e.g., "In most ways my life is close to my ideal") and a 7-point Likert scale (1 = strongly disagree, 7 = strongly agree $)$ (Pavot \& Diener, 1993). The estimated internal consistency reliability in this study was .82. The Persian version of this instrument has also been previously used (e.g., Kjell, Nima, Sikström, 
292 Archer \& Garcia, 2013) and has been found to have a Cronbach's alpha of .89 (for other studies

293 see Yoo \& Lee, 2005; Edward \& Lopez, 2006; Vera et al., 2008).

\section{Procedures}

295 With permission from its author (personal communication, 2013), the MEIM was translated

296 into Persian and back-translated to English by a research team (a linguist and two mental health

297 experts) fluent in both Persian and English languages (Guillemin, Bombardier, \& Beaton, 1993;

298 Villagran, \& Lucke, 2005). A primary Persian version of the MEIM was prepared and its clarity was evaluated by means of a pilot study on 30 students (15 females) who were asked to rate the fluency of items from 0 (Not Understandable) to 5 (Completely Understandable). In this pilot study, participants were asked to report any misunderstanding or lack of clarity related to concepts or wording. The most common rating by participants was completely understandable (response option number five), with this response option endorsed at 95\% or higher across all items. Thus, participants' responses indicated no need for item revision. The back-translation was done by other mental health and linguistic professionals. The back-translation followed by experts ` judgments revealed that, apart from a few minor adjustments, regarding wording and layout, the Persian version of the MEIM was a precise reflection of its original version. Ethical approval for carrying the study was obtained from The Shahid Beheshti University's ethics board (95-03-211-31609). To carry out the sampling process, using convenience sampling, research assistants at The Shahid Beheshti University invited students to participate in the study. The ones who accepted the invitation, were handed the questionnaires in in their classrooms in a group survey administration format. Before asking participants to sign the 
314 study whenever they wanted to do so, they were given brief description about the aim of the

315 study, and informed about the confidentiality of their participation. The three questionnaires

316 were distributed in different orders, that is, in a counterbalanced design to control for order-

317 effect. The questionnaires included the MEIM, the PANAS, the SWLS, and a demographic

318 information sheet (i.e., gender, age, marital status, and educational status).

\section{Statistical Strategy}

320 A CFA using LISREL, version 8.72 (Jöreskog and Sörbom, 2005) was applied to examine the two-

321 factor structure of the MEIM (cf. Phinney, 1992, 1998). This method offers a variety of

322 statistical tests and indices designed to assess the "goodness-of- fit" of identified models

323 (Mulaik, James, Van Alstine, Bennett, Lind, Stilwell, 1989). For this purpose, in the present

324 study, the goodness-of-fit was evaluated using the following statistics: the goodness-of-fit index

$325($ GFI > .9), the adjusted goodness-of-fit index (AGFI > .90), the non-normal fit index (NNFI > .90),

326 the comparative fit index (CFI $>.90)$, the root mean square residual (RMSR $<.08)$, the normal

327 chi-square $\left(3>\chi^{2} / \mathrm{df}<2\right)$ and the root mean square error of approximation (RMSEA) and its $90 \%$

328 confidence interval (<.05: Breckler, 1990; Mulaik et al., 1989). In short, the extent to which

329 present data was compatible with different models (and modifications) was examined using

330 LISREL, version 8.72 (Joreskog \& Sorbom, 2005). The first model specified a one-factor model

$331\left(M_{1}\right)$ in which all 12 items were forced to load on a single global factor (i.e., Reese et al., 1998);

332 the second model presented a two-factor orthogonal model $\left(M_{2}\right)$; the third examined a two-

333 factor oblique model $\left(M_{3}\right)$ as reported in the EFA procedure by Phinney $(1992,1998)$. The

334 concurrent validity of the MEIM was investigated by correlations between the MEIM scores and

335 the subjective well-being scores. To evaluate the test-retest reliability of the MEIM, Intra-class 
336

337

338

339

340

341

342

343

344

345

correlation coefficients, for the total scale and the two sub-scales, were calculated on two occasions over four weeks apart. Cronbach's alpha and mean inter-item correlation coefficients were calculated for the total MEIM score and its sub-scales. Preliminary analysis of the data showed that normality was violated. The $Z$ score for the univariate skewness values ranged from -4.40 [Item 9, "I have a lot of pride in my ethnic group"] to -.76 [Item 1, "I have spent time trying to find out more about my ethnic group, such as its history, traditions, and customs."]

(See Table 2), and Relative Multivariate Kurtosis was 1.16 and test of multivariate normality for skewness and kurtosis was $\chi^{2}=255.29, p<.001$. Due to univariate and multivariate nonnormality of the MEIM items, the weighted least squares (WLS) estimation method was applied in CFA (Bentler \& Bonett, 1980).

\section{Aim 1: Factorial Validity and Test-Retest Reliability of the MEIM}

Table 2 presents the fit estimates for all models. The one-factor model and the two-factor orthogonal model did not meet the previously specified fit criteria and the two factors oblique model showed inadequate fit to the data $\left(M_{1}\right.$ to $\left.M_{3}\right)$. The modification by correcting errors in the two-factor model revealed some improvement $\left(\mathrm{M}_{3 a} ; R M S E A=.053\right)$. The chi-square test results were significant for all models, but that is to be expected with models with large degrees of freedom and relatively large sample sizes (Bentler, 1995). An examination of the remaining fit indices (Satorra and Bentler, 2001) for nested models suggested that the oblique and correlated errors model ( $\mathrm{M}_{3 \mathrm{a}}$ in table 2$)$ was significantly more acceptable than the two factors oblique model $\left(M_{3} ; \Delta \chi^{2}=102.07 ; d f=4, P<.001\right)$. In a comparison of the nested 
357 models, the $\Delta \chi^{2}$ (Jöreskog and Sörbom, 1993) showed that the two-factor oblique correlated

358 errors model provided a better fit $\left[S-B \chi^{2} / d f=2.19 ; C F I=.90 ; N N F I=.88 ;\right.$ and $R M S E A=.053([\mathrm{Cl}]$

$35990 \%=.039, .067]$. The correlation found between exploration and commitment latent variables

360 was .88 $(p<.001)$.

Another series of CFAs were conducted in order to determine if the factorial structure of

362 the MEIM was consistent across gender. In short, testing the factor structure of MEIM in both

363 males and females is the main starting point in evaluating multivariate CFA across genders and

364 building baseline models for each group separately without any specification of equality

365 constrained across groups. For testing equivalency across genders, both baseline models were

366 modified to include the specification of four error covariances for males, and for females. First,

367 a CFA was conducted for males and females separately. Several steps were taken in order to

368 obtain satisfactory model fit and these steps were guided by parsimony and meaningfulness

369 perspectives (Byrne, Shavelson, \& Muthén 1989). The comparison of the baseline model $\left(\chi^{2} / \mathrm{df}\right.$

$370=1.55 ; \mathrm{CFI}=.93 ; \mathrm{NNFI}=.91 ;$ and RMSEA $=.051([\mathrm{Cl}] 90 \%=.034, .066)$ and the modified models

371 for males $\left(\mathrm{M}_{\mathrm{m}} ; \chi^{2} / \mathrm{df}=1.72 ; \mathrm{CFI}=.91 ; \mathrm{NNFI}=.88\right.$; and $\mathrm{RMSEA}=.056([\mathrm{Cl}] 90 \%=.035, .076)$ and

372 females $\left(\mathrm{M}_{\mathrm{f}} ; \chi^{2} / \mathrm{df}=1.38 ; \mathrm{CFI}=.96 ; \mathrm{NNFI}=.94 ;\right.$ and $\mathrm{RMSEA}=.044([\mathrm{Cl}] 90 \%=.0095, .069)$,

373 indicated that the modified models for males $\left(\Delta \chi^{2}=67.47, d f=49, p<.05\right)$, and for females

$374\left(\Delta \chi^{2}=84.51 .4, d f=49, p<.01\right)$ were significantly different from the diagonal error covariance

375 baseline model. Hence, these models provided an adequate level of fit for males and females as

376 baseline models. Table 2 (model $M_{b}$ ) shows that the hypothesized factor structure of MEIM

377 revealed good fit across genders, but the pattern of factor loadings (model $M_{c}$ ) varied across

378 genders (Table 2). All constrained models in Table 2 were compared with $\chi^{2}$ statistics against a 
379 starting or baseline model $\left(\mathrm{M}_{\mathrm{b}}\right)$ in which no constraints in estimation of parameters were

380 specified. The results indicated that the variances and covariance of commitment and

381 exploration were consistent across gender.

382

In the case of configural invariance, $\chi^{2}, \mathrm{RMSEA}, \mathrm{CFI}, \mathrm{NNFI}$, and other fit indices were

used to examine whether or not the combined models had a good model fit. Furthermore, for

metric, scalar, residual, and latent variances and covariance, the RMSEA values and RMSEA

confidence intervals of the hierarchical (nested) models were compared. For example, in the

case of comparison of the weak and strong factorial invariance models, if RMSEA values fall

within one another's confidence intervals, this shows strong factorial invariance. Then, the

the weak and strong factorial invariance models was assessed. A change of less than .01 shows

strong factorial invariance (Cheung \& Rensvold, 2002). That is, it shows equal form (i.e. the

loadings, equal thresholds (i.e. when observed scores are regressed on each factor, the

thresholds are equal), and equal residual variances across gender.

suggest that the scale has acceptable internal consistency. For test-retest reliability of the 
400

401

402

403

404

405

406

407

408

409

410

411

412

413

414

415

416

417

418

419

420

421

\section{Aim 2: Concurrent Validity of the MEIM}

Table 5 presents the Pearson correlation coefficients between MEIM and its subscales with positive affect, negative affect, and life satisfaction. The results indicate that, as expected, the MEIM and its subscales have a positive relationship with positive affect and Life satisfaction and a negative relationship with negative affect. The shared variance for the total score of the MEIM indicates weak relationships between ethnic identity and subjective well-being measures.

\section{Aim 3: Gender Differences and Ethnic Identity}

A noticeably different pattern of results was found for males and females (Table 3). Female students had a significantly higher score on the MEIM compared to male students $(t(424)=$ $2.71, p=.007)$. A multivariate analysis of variance (MANOVA) was conducted to evaluate the effects of gender on the MEIM sub-scales, with Bonferroni adjustment for multiple comparisons (Huberty \& Morris, 1989). The MANOVA results showed a significant effect: Hotelling's Trace = $.02, F(3,1158)=4.33, p=.014, \eta^{2}=.02$ (Table 3). Subsequent examination of between-subject effects showed that the female group scored significantly higher on exploration $(F(1,402)$ $\left.=7.50, p=.003, \eta^{2}=.018\right)$ and commitment $\left(F(1,402)=4.99, p=.016, \eta^{2}=.014\right)$.

The purpose of this study was to confirm the factor structure, reliability, test-retest and concurrent validity of the Persian version of the MEIM in a sample of young Iranian adults, and to see if there are any gender differences of ethnic identity in the sample. Generally, the scale was found to be reliable and valid for young adults and both genders. This study serves an important purpose since ethnic identity plays a major role in normal development and positive 
422 youth adjustment (Rivas-Drake et al., 2014). Although a lot of research has been done on ethnic

423 identity, the majority of these studies have focused on different ethnic groups within the

424 American population and context (e.g. Rivas-Drake et al., 2014; Roberts et al., 1997; Yap et al.,

425 2011). Due to the fact that a variety of ethnicities exist in Iran, and also because a significant

426 population in the world speak Persian including Iranians, Afghanis, Tajikistanis, and also many

427 immigrants in other countries such as USA, UAE, Canada and Turkey, we found it important to

428 investigate the psychometric properties of the Persian version of the 12 -item MEIM. The results

429 indicated that a two-factor oblique with correlated errors model $\left(M_{3 a}\right)$ fit the data better than

430 the two other models $\left(M_{1}\right.$ to $\left.M_{2}\right)$. All 12 items were loaded on their respective factors, and

431 factor loadings ranged from .54 to .78 for the exploration factor, and from .71 to .90 for the

432 commitment factor. This suggests that the best way to interpret the MEIM scores would be to

433 consider one global score and two sub-scores (i.e., exploration and commitment). Indeed, a

434 similar hierarchical model was suggested by Phinney and Ong (2007), as a model with generally

435 acceptable (not the best) fit criteria for the revised version of the MEIM in English (MEIM-R).

436 The Cronbach's alpha coefficients (.75 - .92), mean inter-item correlations (.38 - .59),

437 and intra-class coefficients between two points in time with a four-week interval (.82 - .91), all

438 support the reliability of the Persian version of the MEIM across genders. These findings are

439 consistent with previous research indicating good internal reliability for the MEIM in other

440 cultures (Cuellar, Nyberg, Maldonado, \& Roberts, 1997; Dandy et al., 2008; Lee, Falbo, Doh, \&

441 Park, 2001; Phinney, 1992; Ponterotto et al., 2003; Spencer et al., 2000; Yip \& Fuligni, 2002).

442 Moreover, the construct validity of the MEIM was supported by the relatively modest,

443 albeit statistically significant, correlations between both its total and subscales scores and 
444 measures of subjective well-being (e.g. positive affect, negative affect and life satisfaction). All

445 correlations were in the expected directions, thus, replicating earlier studies (e.g., Beiser \& Hou,

446 2006; Dandy et al., 2008; Juang \& Syed, 2010; Kiang, Yip, Gonzales-Backen, Witkow, \& Fuligni,

447 2006; Martinez \& Dukes, 1997; Phinney \& Ong, 2007; Roberts et al., 1999). More specifically,

448 consistent with previous findings, we found positive relationships between ethnic identity (both

449 total and subscales scores) and both positive affect (cf. Dimitrova, Bender, Chasiotis, \& van de

450 Vijver, 2013; Juang \& Syed, 2010) and life satisfaction (cf. Dimitrova et al., 2013; Dimitrova,

451 Ferrer-Wreder, \& Trost, 2015; Dimitrova, Johnson, \& van de Vijver, 2017; Juang \& Syed,

452 2010; Williams, Chapman, Wong, \& Turkheimer, 2012), while ethnic identity (both total and

453 subscales scores) was found to be negatively related to negative affect (Abu-Rayya, 2006;

454 Beiser \& Hou, 2006; Dimitrova et al., 2013; Juang \& Syed, 2010). Given that ethnic identity is

455 only one of the many correlates of subjective well-being, the relatively small effect size in these

456 correlations seems rational. However, regarding the construct validity issue, the directions of

457 the relations are of particular significance.

458

With regard to gender, we found significantly higher scores in ethnic identity and its two

459

components (exploration and commitment) in women compared to men. This finding is in line

460 with some of the previous research (e.g., Dion \& Dion, 2001; Juang \& Syed, 2010;

461 Suárez-Orozco \& Qin, 2006). Gender differences may lie in the fact that women more

462 commonly feel that they are expected and even pressurized to preserve their cultural and

463 ethnic values (Juang \& Syed, 2010; Yip \& Fuligni, 2002). Indeed, in the Iranian culture women

464 are often told to act like a "Khanoum", which means "lady", which is an expression mirroring

465 society's expectation that women should be committed to and act in congruence with 
466 sociocultural norms and pre-defined values (Rashidian, Hussain and Minichiello, 2013). Such

467 expectations can influence Iranian females define themselves by their ethnic identity and too

468 seek the validation of their ethnic groups and the broader society in order to be honored with

469 the "noble" title of "Khanoum". Furthermore, in the Iranian context, when a female deviates

470 from their ethno-cultural values and codes of behavior, the repercussions they face is far

471 greater than that a male facing the similar situation-for a female, this might mean losing her

472 family support altogether. The need to receive the family's validation and acceptance is, for

473 instance, one of the important needs expressed by Iranian adolescent girls, as suggested in the

474 qualitative study conducted by Mousavi and her colleagues among 27 Iranian adolescent girls

475 (Mousavi, Shahriari, Salehi and Kohan, 2018).

476 Conclusions, Limitations, and Future Directions

477 In conclusion, the results from this study provide support for the validity, reliability and factor

478 structure of the Persian version of the 12-item MEIM in a young adult sample. The results

479 generally support the use of the 12-item MEIM among Iranian young adults. We propose that

480 the MEIM is specially suitable for research on ethnic identity in Iran which is a multiethnic

481 country; since the MEIM is a widely used instrument and it was designed to be utilized across

482 different ethnic groups (Phinney, 1992). Hence, its validation in an Iranian context was of great

483 importance. It is also very useful for comparing variances in ethnic identity and well-being

484 among people from different countries that, for one reason or another, live in another country

485 as immigrants. Moreover, the validation of the MEIM in the Iranian context facilitates the

486 comparison of research findings to those from other cultures in which this widely spread

487 instrument has been used. 
adolescents (e.g., 12-17 years old). In this vein, since the population in this study was limited to

importance if the research issues are related in any way to gender; since our study shows that

MEIM-R version of this instrument is also confirmed by Phinney and Ong (2007) as a tool that

ethnic identity within ethnic minority groups in Iran, which was not possible in this study due to investigations of the OGO-scale and of the El-factor structure.

That all being said, the findings of this study provide useful information, adding to the

existing literature on ethnic identity in Iran. Hence, laying the groundwork for further studies on other aspects of ethnic identity in the Iranian context and other ethnic groups around the world.

\section{Acknowledgement}

508 The development of this article was funded by a grant from the Swedish Research Council (Dnr. 
510 publish, or preparation of the manuscript. The researchers would also like to thank the students

511 who participated in this study. 


\section{REFERENCES}

513 Abu-Rayya, H. M. (2006). Ethnic self-identification and psychological well-being among

514 adolescents with European mothers and Arab fathers in Israel. International Journal of

515 Intercultural Relations, 30(5), 545-556. DOI: 10.1016/j.ijintrel.2005.10.003

516 Ali, M. (2006). Impact of acculturation, ethnic identity, religiosity, and individual difference variables on the subjective well-being of Pakistani Muslims in the United States: Southern Illinois University at Carbondale. UMI Number: 3229824

519

520

521

522

523

524

525

526

527

528

529

530

531

532

533

Alijani, M. (2006). The relationship between religious identity and mental health in students of Islamic Azad University. Journal of Psychological Studies, 1, 89-106. (In Persian).

Amanolahi, S. (2005). A note on ethnicity and ethnic groups in Iran. Iran and the Caucasus, 9(1), $37-42$

Beiser, M. N., \& Hou, F. (2006). Ethnic identity, resettlement stress and depressive affect among Southeast Asian refugees in Canada. Social science \& medicine, 63(1), 137-150. DOI: 10.1016/j.socscimed.2005.12.002

Bentler, P. M., \& Bonett, D. G. (1980). Significance tests and goodness of fit in the analysis of covariance structures. Psychological bulletin, 88(3), 588. DOI: 10.1037/00332909.88.3.588

Bentler, P. M., \& Chou, C. P. (1987). Practical issues in structural modeling. Sociological Methods \& Research, 16(1), 78-117. DOI: 10.1177/0049124187016001004

Bernal, M. E., \& Knight, G. P. (Eds.). (1993). SUNY series, United States Hispanic studies. Ethnic identity: Formation and transmission among Hispanics and other minorities. State University of New York Press. 
534 Bernard, M. E., Vernon, A., Terjesen, M., \& Kurasaki, R. (2013). Self-acceptance in the education 535 and counseling of young people The strength of self-acceptance (pp. 155-192): Springer. DOI: 10.1007/978-1-4614-6806-6_10

537

538

539

540

541

542

543

544

545

546

547

548

549

550

551

552

553

554

555

Burrow-Sanchez, J. J. (2014). Measuring ethnic identity in Latino adolescents with substance use disorders. Substance Use \& Misuse, 49(8), 982-986. DOI:

$10.3109 / 10826084.2013 .794839$

Cislo, A. M. (2008). Ethnic identity and self-esteem: Contrasting Cuban and Nicaraguan young adults. Hispanic Journal of Behavioral Sciences, 30(2), 230-250. DOI:

$10.1177 / 0739986308315297$

Cloninger, C. R. (2004). Feeling good-the science of well-being. New York: Oxford University Press.

Cloninger, C. R., Garcia, D., \& Pluess, M. (2015). The heritability and development of positive affect and emotionality. Genetics of psychological well-being-the role of heritability and genetics in positive psychology, 97-113.

Creagh-kaiser, M. G. (2003). The influence of ethnic identity gender and trait anxiety on career decision-making self-efficacy for white and racial/ethnic minority students. Phd Dissertation, Seton Hall University. (ETDs). 1625. https://scholarship.shu.edu/dissertations/1625

Cuellar, I., Nyberg, B., Maldonado, R. E., \& Roberts, R. E. (1997). Ethnic identity and acculturation in a young adult Mexican-origin population. Journal of community psychology, 25(6), 535-549. DOI: 10.1002/(SICI)1520-6629(199711)25:6<535::AIDJCOP4>3.0.CO;2-O 
556 Dandy, J., Durkin, K., McEvoy, P., Barber, B. L., \& Houghton, S. (2008). Psychometric properties

557 of multigroup ethnic identity measure (MEIM) scores with Australian adolescents from

558 diverse ethnocultural groups. Journal of Adolescence, 31(3), 323-335. DOI:

$559 \quad$ 10.1016/j.adolescence.2007.06.003

560 Diener, E., Lucas, R. E., \& Oishi, S. (2018). Advances and open questions in the science of $561 \quad$ subjective well-being. Collabra. Psychology, 4(1).

562 Dimitrova, R., Bender, M., Chasiotis, A., \& van de Vijver, F. J. (2013). Ethnic identity and acculturation of Turkish-Bulgarian adolescents. International Journal of Intercultural Relations, 37(1), 1-10. DOI: 10.1016/j.ijintrel.2012.04.005

Dimitrova, R., Ferrer-Wreder, L., \& Trost, K. (2015). Intergenerational transmission of ethnic identity and life satisfaction of Roma minority adolescents and their parents. Journal of adolescence, 45, 296-306. DOI: 10.1016/j.adolescence.2015.10.014

Dimitrova, R., Johnson, D. J., \& van de Vijver, F. J. (2018). Ethnic socialization, ethnic identity, life satisfaction and school achievement of Roma ethnic minority youth. Journal of adolescence, 62, 175-183. DOI: 10.1016/j.adolescence.2017.06.003

Dion, K. K., \& Dion, K. L. (2001). Gender and cultural adaptation in immigrant families. Journal of Social Issues, 57(3), 511-521. DOI: 10.1111/0022-4537.00226 satisfaction in mexican american youth: A mixed-methods exploration. Journal of counseling psychology, 53(3), 279. DOI: 10.1037/0022-0167.53.3.279 
577 Esteban, M., Nadal, J. M., \& Vila, I. (2010). Ethnic identity among indigenous and mestizos from $578 \quad$ Intercultural University of Chiapas. Escritos de Psicología-Psychological Writings, 3(3), 15579 21. DOI: $10.5231 /$ psy.writ.2010.0604

580 French, S. E., Seidman, E., Allenb, L., \& Aber, J. L. (2006). The development of ethnic identity during adolescence. Developmental Psychology, 42, 1-10. DOI: 10.1037/0012-1649.42.1.1 582 Garcia, D., \& Archer, T. (2012). Adolescent life satisfaction and well-being. Journal of Alternative $583 \quad$ Medicine Research, 4(3), 271.

584 Garcia, D., Nima, A. A., Granjard, A., \& Cloninger, K. M. (In press). Bring Balance to the Force! A 585 Biopsychosocial Model of Subjective Well-Being: Affectivity, Life Satisfaction, and 586 Harmony in Life. International Journal of Person Centered Medicine.

Garcia, D., Nima, A. A, \& Kjell, O. N. (2014). The affective profiles, psychological well-being, and 588 harmony: environmental mastery and self-acceptance predict the sense of a harmonious life. PeerJ, 2, e259. DOI: 10.7717/peerj.259

Garcia, D., \& Siddiqui, A. (2009). Adolescents' Psychological Well-Being and Memory for LifeEvents: Influences on Life Satisfaction with Respect to Temperamental Dispositions.Journal of Happiness Studies, 10, 387-503. DOI: 10.1007/s10902-008-9096-3. Affective Temperaments and the Influence of Negative Stimuli on Memory. Journal of Happiness Studies, 11, 477-495. DOI: 10.1007/s10902-009-9153-6.

Ghazanfari, A. (2003). Effect of identity and coping strategies on mental health of high school students. Phd Dissertation, Tabatabai University. (In Persian). 
598 Gilman, R., Huebner, E. S., \& Laughlin, J. E. (2000). A first study of the Multidimensional

$599 \quad$ Students' Life Satisfaction Scale with adolescents. Social Indicators Research, 52(2), 135-

600 160. DOI: $10.1023 / A: 1007059227507$

601 Go, C. g., \& Le, T. N. (2005). Gender differences in Cambodian delinquency: The role of ethnic

602 identity, parental discipline, and peer delinquency. Crime \& Delinquency, 51(2), 220-237.

$603 \quad$ DOI: $10.1177 / 0011128704273466$

604 Guillemin, F., Bombardier, C., \& Beaton, D. (1993). Cross-cultural adaptation of health-related

605 quality of life measures: literature review and proposed guidelines. Journal of clinical

606 epidemiology, 46(12), 1417-1432. DOI: 10.1016/0895-4356(93)90142-N

607 Gulyas, A. (2017). Hybridity and social media adoption by journalists: An international

608 comparison. Digital Journalism, 5(7), 884-902. DOI: 10.1080/21670811.2016.1232170

609 Hajiyani, A. (2008). Proportion of national identity, ethnic identity among Iranian ethnics.

610 Journal of Iranian Sociological, 9(3), 143-164. (In Persian).

611 Hejazi, E., Shahraray, M., Farsinejad, M., \& Asgary, A. (2009). Identity styles and academic

612 achievement: Mediating role of academic self-efficacy. Social Psychology of Education,

613 12(1), 123-135. DOI: 10.1007/s11218-008-9067-x

614 Herrington, H. M., Smith, T. B., Feinauer, E., \& Griner, D. (2016). Reliability generalization of the 615 Multigroup Ethnic Identity Measure-Revised (MEIM-R). Journal of counseling psychology, 616 63(5), 586. DOI: $10.1037 /$ cou0000148

617 Homma, Y., Zumbo, B. D., Saewyc, E. M., \& Wong, S. T. (2014). Psychometric evaluation of the 618 six-item version of the Multigroup Ethnic Identity Measure with East Asian adolescents in 619 Canada. Identity, 14(1), 1-18. DOI: 10.1080/15283488.2013.858227 
620 Huberty, C. J., \& Morris, J. D. (1992). Multivariate analysis versus multiple univariate analyses.

621

DOI: • 10.1037/0033-2909.105.2.302

622 Igundunasse, A., \& Dada, A. Testing the Validity of the Multigroup Ethnic Identity Measure 623 (MEIM) on a Nigerian Sample. DOI: 10.1037/10109-030

624 Ivory, L. I. (2003). Ethnic identity, college academic self-efficacy, and academic performance of 625 African American and Puerto Rican college students under the aegis of a higher education $626 \quad$ opportunity program.

627 Iwamoto, D. K., \& Liu, W. M. (2010). The impact of racial identity, ethnic identity, Asian values, 628 and race-related stress on Asian Americans and Asian international college students'

629 psychological well-being. Journal of counseling psychology, 57(1), 79. DOI: 10.1037/a0017393

630 Jöreskog, K. G., \& Sörbom, D. (2005). Lisrel (Version 8.72). Lincolnwood, Illinois: Scientific 631 Software International.

632 Jöreskog, K. G., \& Sörbom, D. (1993). LISREL 8: Structural equation modeling with the SIMPLIS 633 command language. Scientific Software International; Lawrence Erlbaum Associates, Inc. 634 Juang, L., \& Syed, M. (2010). Family cultural socialization practices and ethnic identity in 635 college-going emerging adults. Journal of Adolescence, 33(3), 347-354. DOI: 10.1016/j.adolescence.2009.11.008

Kazarian, S. S., \& Boyadjian, M. D. (2008). Validation of the multigroup ethnic identity measure 638 among ethnic Armenian adolescents in Lebanon. Identity: An International Journal of Theory and Research, 8(4), 335-347. DOI: 10.1080/15283480802365312 
640 Kiang, L., \& Fuligni, A. J. (2009). Ethnic identity and family processes among adolescents from 641 Latin American, Asian, and European backgrounds. Journal of Youth and Adolescence, 642 38(2), 228-241. doi: 10.1007/s10964-008-9353-0.

643

644

645

646

647

648

649

650

651

652

653

654

655

656

657

658

659

660

661 the daily psychological well-being of adolescents from Mexican and Chinese backgrounds.

Child development, 77(5), 1338-1350. DOI: 10.1111/j.1467-8624.2006.00938.x

Kjell, O. N., Nima, A. A., Sikström, S., Archer, T., \& Garcia, D. (2013). Iranian and Swedish

adolescents: differences in personality traits and well-being. PeerJ, 1, e197. DOI:

10.7717/peerj.197

Krieger, A. (2010). The role of family functioning in ethnic identity and well-being in Jewish late adolescent women. University of Rhode Island.

Lee, R. M., \& Yoo, H. C. (2004). Structure and Measurement of Ethnic Identity for Asian American College Students. Journal of Counseling Psychology, 51(2), 263-269. Doi.10.1037/0022-0167.51.2.263

Lee, R. M., Falbo, T., Doh, H. S., \& Park, S. Y. (2001). The Korean diasporic experience: Measuring ethnic identity in the United States and China. Cultural Diversity and Ethnic Minority Psychology, 7(3), 207. DOI: 10.1037/1099-9809.7.3.207

Lucas, R. E., Diener, E., \& Suh, E. (1996). Discriminant validity of well-being measures. Journal of personality and social psychology, 71(3), 616. DOI: 10.1037/0022-3514.71.3.616

Maclnnes, D. L. (2006). Self-esteem and self-acceptance: an examination into their relationship and their effect on psychological health. Journal of psychiatric and mental health nursing, 13(5), 483-489. DOI: 10.1111/j.1365-2850.2006.00959.x

Peer) reviewing PDF | (2018:08:30282:2:0:NEW 16 Dec 2020) 
662 Martinez, R. O., \& Dukes, R. L. (1997). The effects of ethnic identity, ethnicity, and gender on 663 adolescent well-being. Journal of youth and adolescence, 26(5), 503-516. DOI:

664 10.1023/A:1024525821078Marcia, J. (1980). Identity in adolescence. In J. Adelson (Ed.), 665 Handbook of adolescent psychology (pp. 159 -187). New York: Wiley.

666

667

668

669

670

671

672

673

674

675

676

677

678

679

680

681

682

Moghaddas Jafari, M. h., Sheikhavandi, D., \& Sharif Pour, H. (2008). Correlation between national identity and ethnic identity among Kurdish youth: A Case study. Saqqez Payam-eNoor University. National studies, 33(9), 97-126. (In Persian).

Mossakowski, K. N. (2018). Are There Gender Differences in the Psychological Effects of Ethnic Identity and Discrimination in Hawai 'i?. Hawai'i Journal of Medicine \& Public Health, 77(11), 289.

Mousavi, M., Shahriari, M., Salehi, M., \& Kohan, S. (2018). How Is Developing the Sense of Belonging in Iranian Adolescent Girls? A Qualitative Study. Open access Macedonian journal of medical sciences, 6(5), 885. DOI: 10.3889/oamjms.2018.170

Mulaik, S. A., James, L. R., Van Alstine, J., Bennett, N., Lind, S., \& Stilwell, C. D. (1989). Evaluation of goodness-of-fit indices for structural equation models. Psychological bulletin, 105(3), 430. DOI: 10.1037/0033-2909.105.3.430

Myers, D. G., \& Diener, E. (1995). Who is happy?. Psychological science, 6(1), 10-19. DOI: 10.1111/j.1467-9280.1995.tb00298.x

Navarrete, C. D., McDonald, M. M., Molina, L. E., \& Sidanius, J. (2010). Prejudice at the nexus of race and gender: an outgroup male target hypothesis. Journal of personality and social psychology, 98(6), 933. DOI: 10.1037/a0017931 
683 Nima, A. A., Cloninger, K. M., Luchesse, F., Sikström, S., \& Garcia, D. (2020). Validation of a 684 General Subjective Well-Being Factor Using Classic Test Theory. PeerJ, 8:e9193. DOI:

685 10.7717/peerj.9193.

686

687

688

689

690

691

692

693

694

695

696

697

698

699

700

701

702

703

704

Nima, A. A., Cloninger, K. M., Persson, B. N., Sikström, S., \& Garcia, D. (2020). Validation of Subjective Well-Being Measures using Item Response Theory. Frontiers in Psychology, 10: 3016. DOI: 10.3389/fpsyg.2019.03036.

Oliveira, D. R. D., Pankalla, A., \& Cabecinhas, R. (2012). Ethnic Identity as predictor for the wellbeing: An exploratory transcultural study in Brazil and Europe. Summa psicológica UST (En línea), 9(2), 33-42.

Ong, A. D., Phinney, J. S., \& Dennis, J. (2006). Competence under challenge: Exploring the protective influence of parental support and ethnic identity in Latino college students. Journal of adolescence, 29(6), 961-979. DOI: 10.1016/j.adolescence.2006.04.010

Ontai-Grzebik, L. L., \& Raffaelli, M. (2004). Individual and social influences on ethnic identity among Latino young adults. Journal of Adolescent Research, 19(5), 559-575. DOI: $10.1177 / 0743558403260002$

Pavot, W., \& Diener, E. (2009). Review of the satisfaction with life scale. In Assessing well-being (pp. 101-117). Springer, Dordrecht. DOI: 10.1007/978-90-481-2354-4_5

Pavot, W., \& Diener, E. (2004). Findings on subjective well-being: Applications to public policy, clinical interventions, and education. In A. P. Linely \& S. Joseph (Eds.), Positive psychology in practice. Hoboken, NJ: Wiley. 679-692.

Pegg, P. O., \& Plybon, L. E. (2005). Toward the theoretical measurement of ethnic identity. The Journal of Early Adolescence, 25(2), 250-264. DOI: 10.1177/0272431604274175 
705 Phinney, J. S. (1991). Ethnic identity and self-esteem: A review and integration. Hispanic journal 706 of behavioral sciences, 13(2), 193-208. DOI: 10.1177/07399863910132005

707 Phinney, J. S. (1992). The multigroup ethnic identity measure: A new scale for use with diverse 708 groups. Journal of adolescent research, 7(2), 156-176. DOI: 10.1177/074355489272003

709

710

711

712

713

714

715

716

717

718

719

720

721

722

723

724

Phinney, J. S., \& Rosenthal, D. A. (1992). Ethnic identity in adolescence: Process, context, and outcome. In G. R. Adams, T. P. Gullotta, \& R. Montemayor (Eds.), Advances in adolescent development, Vol. 4. Adolescent identity formation (p. 145-172). Sage Publications, Inc.

Phinney, J. S., \& Ong, A. D. (2007). Conceptualization and measurement of ethnic identity: Current status and future directions. Journal of counseling Psychology, 54(3), 271. DOI: 10.1037/0022-0167.54.3.271

Phinney, J. S., Cantu, C. L., \& Kurtz, D. A. (1997). Ethnic and American identity as predictors of self-esteem among African American, Latino, and White adolescents. Journal of Youth and adolescence, 26(2), 165-185. DOI: 10.1023/A:1024500514834

Ponterotto, J. G., Gretchen, D., Utsey, S. O., Stracuzzi, T., \& Saya Jr, R. (2003). The multigroup ethnic identity measure (MEIM): Psychometric review and further validity testing. Educational and Psychological Measurement, 63(3), 502-515. DOI: $10.1177 / 0013164403063003010$

Rashidian, M., Hussain, R., \& Minichiello, V. (2013). 'My culture haunts me no matter where I go': Iranian-American women discussing sexual and acculturation experiences. Culture, health \& sexuality, 15(7), 866-877. 
725 Rashidian, M., Hussain, R., \& Minichiello, V. (2013). 'My culture haunts me no matter where I

726 go': Iranian-American women discussing sexual and acculturation experiences. Culture,

727 health \& sexuality, 15(7), 866-877. DOI: 10.1080/13691058.2013.789128

728 Rivas-Drake, D., Seaton, E. K., Markstrom, C., Quintana, S., Syed, M., Lee, R. M., ... \& Ethnic and

729

730

731

732

733

734

735

736

737

738

739

740

741

742

743

744

745

Racial Identity in the 21st Century Study Group. (2014). Ethnic and racial identity in adolescence: Implications for psychosocial, academic, and health outcomes. Child development, 85(1), 40-57. DOI: 10.1111/cdev.12200

Roberts, R. E., Phinney, J. S., Masse, L. C., Chen, Y. R., Roberts, C. R., \& Romero, A. (1999). The structure of ethnic identity of young adolescents from diverse ethnocultural groups. The Journal of Early Adolescence, 19(3), 301-322. DOI: 10.1177/0272431699019003001

Saleh, A. (2013). Ethnic Conflict in Iran Ethnic Identity and the State in Iran (pp. 59-84): Springer.

DOI: $10.1057 / 9781137310873 \_5$

Sarno, E. L., \& Mohr, J. J. (2016). Adapting the multigroup ethnic identity measure to assess LGB group identity. Psychology of Sexual Orientation and Gender Diversity, 3(3), 293. DOI: $10.1037 /$ sgd0000173

Satorra, A., \& Bentler, P. M. (2001). A scaled difference chi-square test statistic for moment structure analysis. Psychometrika, 66(4), 507-514. DOI: 10.1007/BF02296192

Smith, T. B., \& Silva, L. (2011). Ethnic identity and personal well-being of people of color: A meta-analysis. Journal of Counseling Psychology, 58(1), 42. DOI: 10.1037/a0021528

Sobansky, R. R., Song, S. Y., Gutkin, T. B., Galloway, A. M., Yetter, G. P., \& Saunders, A. L. (2010). Moving toward a culturally invariant measure of ethnic identity among diverse 
746

747

748

749

750

751

752

753

754

755

756

757

758

759

760

761

762

763

764

765

766

adolescents: refining the MEIM. International journal of psychology: a biopsychosocial approach, 2010,[Vol.] 7, p. 85-110.

Spencer, M. S., Icard, L. D., Harachi, T. W., Catalano, R. F., \& Oxford, M. (2000). Ethnic identity among monoracial and multiracial early adolescents. The Journal of Early Adolescence, 20(4), 365-387. DOI: 10.1177/0272431600020004001

Suárez-Orozco, C., \& Qin, D. B. (2006). Gendered perspectives in psychology: Immigrant origin youth. International Migration Review, 40(1), 165-198. DOI: 10.1111/j.17477379.2006.00007.x

Swenson, R. R., \& Prelow, H. M. (2005). Ethnic identity, self-esteem, and perceived efficacy as mediators of the relation of supportive parenting to psychosocial outcomes among urban adolescents. Journal of adolescence, 28(4), 465-477. DOI:

10.1016/j.adolescence.2004.09.005

Syed, M., Walker, L. H., Lee, R. M., Umaña-Taylor, A. J., Zamboanga, B. L., Schwartz, S. J., ... \& Huynh, Q. L. (2013). A two-factor model of ethnic identity exploration: Implications for identity coherence and well-being. Cultural Diversity and Ethnic Minority Psychology, 19(2), 143. DOI: 10.1037/a0030564

Umaña-Taylor, A. J. (2004). Ethnic identity and self-esteem: Examining the role of social Azerbaijanis . Journal of adolescence, 27(2), 139-146. DOI:

10.1016/j.adolescence.2003.11.006

Umaña-Taylor, A. J., Vargas-Chanes, D., Garcia, C. D., \& Gonzales-Backen, M. (2008). A longitudinal examination of Latino adolescents' ethnic identity, coping with 
767

768

769

770

771

772

773

774

775

776

777

778

779

780

781

782

783

784

785

786

787

discrimination, and self-esteem. The Journal of Early Adolescence, 28(1), 16-50. DOI: $10.1177 / 0272431607308666$

Vedder, P., \& Phinney, J. S. (2014). Identity formation in bicultural youth: A developmental perspective. The Oxford handbook of multicultural identity, 335-354.

Vera, E., Thakral, C., Gonzales, R., Morgan, M., Conner, W., Caskey, E., ... \& Dick, L. (2008). Subjective well-being in urban adolescents of color. Cultural diversity and ethnic minority psychology, 14(3), 224. DOI: 10.1037/1099-9809.14.3.224

Villagran, M. M., \& Lucke*, J. F. (2005). Translating communication measures for use in nonEnglish-speaking populations. Communication Research Reports, 22(3), 247-251. DOI: $10.1080 / 00036810500230743$

Vleioras, G., \& Bosma, H. A. (2005). Are identity styles important for psychological well-being?. Journal of adolescence, 28(3), 397-409. DOI: 10.1016/j.adolescence.2004.09.001

Vo, V. T. M. C. (2008). The Relationship Between Ethnic Identity Development and Degree of Self-esteem Among Vietnamese American Students (Doctoral dissertation, California State University, Long Beach).

Waterman, A. S. (2007). Doing well: The relationship of identity status to three conceptions of well-being. IDENTITY: AN INTERNATIONAL JOURNAL OF THEORY AND REASEARCH, 7(4), 289-307. DOI: 10.1080/15283480701600769

Watson, D., Clark, L. A., \& Tellegen, A. (1988). Development and validation of brief measures of positive and negative affect: the PANAS scales. Journal of personality and social psychology, 54(6), 1063. DOI: 10.1037/0022-3514.54.6.1063 
788 Williams, M. T., Chapman, L. K., Wong, J., \& Turkheimer, E. (2012). The role of ethnic identity in

789

790

791

792

793

794

795

796

797

798

799

800

801

802

803

804

805

806

807

808

809

810 symptoms of anxiety and depression in African Americans. Psychiatry research, 199(1), 31-36. DOI: 10.1016/j.psychres.2012.03.049

World Population Review, Iran population 2020 (2019). Retrieved February 4, 2019, from http://worldpopulationreview.com/countries/iran-population/.

Yap, S. C., Donnellan, M. B., Schwartz, S. J., Zamboanga, B. L., Kim, S. Y., Huynh, Q. L., ... \& Castillo, L. G. (2016). Evaluating the invariance of the Multigroup Ethnic Identity Measure across foreign-born, second-generation and later-generation college students in the United States. Cultural Diversity and Ethnic Minority Psychology, 22(3), 460. DOI: 10.1037/cdp0000068

Yap, S. C., Settles, I. H., \& Pratt-Hyatt, J. S. (2011). Mediators of the relationship between racial identity and life satisfaction in a community sample of African American women and men. Cultural Diversity and Ethnic Minority Psychology, 17(1), 89-97. DOI: 10.1037/a0022535.

Lum, R. M. Y. (2009). An Investigation of the Effects of Ethnic Identity on Well-Being of Monoethnic and Multiethnic Children and Adolescents in Malaysia.

Yip, T., \& Fuligni, A. J. (2002). Daily variation in ethnic identity, ethnic behaviors, and psychological well-being among American adolescents of Chinese descent. Child development, 73(5), 1557-1572. DOI: 10.1111/1467-8624.00490

Yoo, H. C., \& Lee, R. M. (2005). Ethnic Identity and Approach-Type Coping as Moderators of the Racial Discrimination/Well-Being Relation in Asian Americans. Journal of Counseling Psychology, 52(4), 497-506. DOI: 10.1037/0022-0167.52.4.497 


\section{Table $\mathbf{1}$ (on next page)}

Studies validating psychometric properties of different versions of the MEIM in different countries and populations. 
2 Table 1

3 Studies validating psychometric properties of different versions of the MEIM in different countries and populations.

\begin{tabular}{|c|c|c|c|c|c|}
\hline Country & Author & Participants & Ethnicity/Race & EFA/CFA & $\begin{array}{c}\text { Reliability } \\
\text { (Alpha) }\end{array}$ \\
\hline \multirow{11}{*}{ USA } & \multirow{11}{*}{$\begin{array}{l}\text { Roberts et al. } \\
\text { (1999) }\end{array}$} & & African American $(\mathrm{n}=$ & \multirow{11}{*}{ EFA } & \\
\hline & & & 1,237); Central American & & Total: .85 \\
\hline & & & $(\mathrm{n}=253) ;$ Chinese & & Factor1: \\
\hline & & $\mathrm{N}=5,423$ & American $(\mathrm{n}=177)$ & & (affirmation, \\
\hline & & Students in sixth to eighth & European American $(\mathrm{n}=$ & & belonging, and \\
\hline & & grades & 755); Indian American (n & & commitment $)=$ \\
\hline & & \multirow[t]{5}{*}{$49 \%$ female, Mage $=12.9$} & $=188) ;$ Mexican & & .84 \\
\hline & & & American $(n=755)$ & & Factor2 (ethnic \\
\hline & & & Pakistani American $(\mathrm{n}=$ & & identity search): \\
\hline & & & 155); Vietnamese & & .70 \\
\hline & & & American $(n=304)$; and & & \\
\hline
\end{tabular}




\begin{tabular}{cccc}
\hline Country & Puthor & Reliability \\
& & Ethnicity/Race & EFA/CFA
\end{tabular}

Pacific Islander $(\mathrm{n}=101)$;

and mixed ancestry $(\mathrm{n}=$

342).

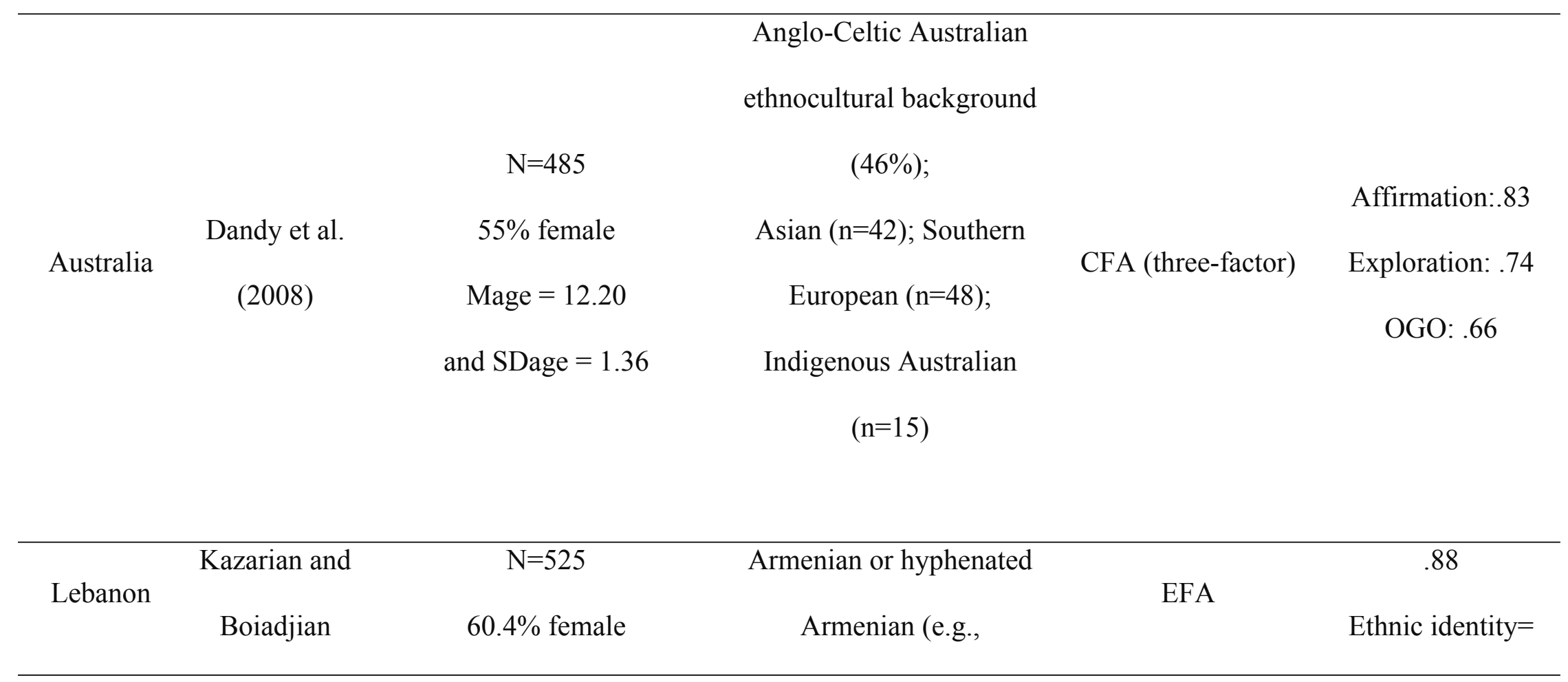




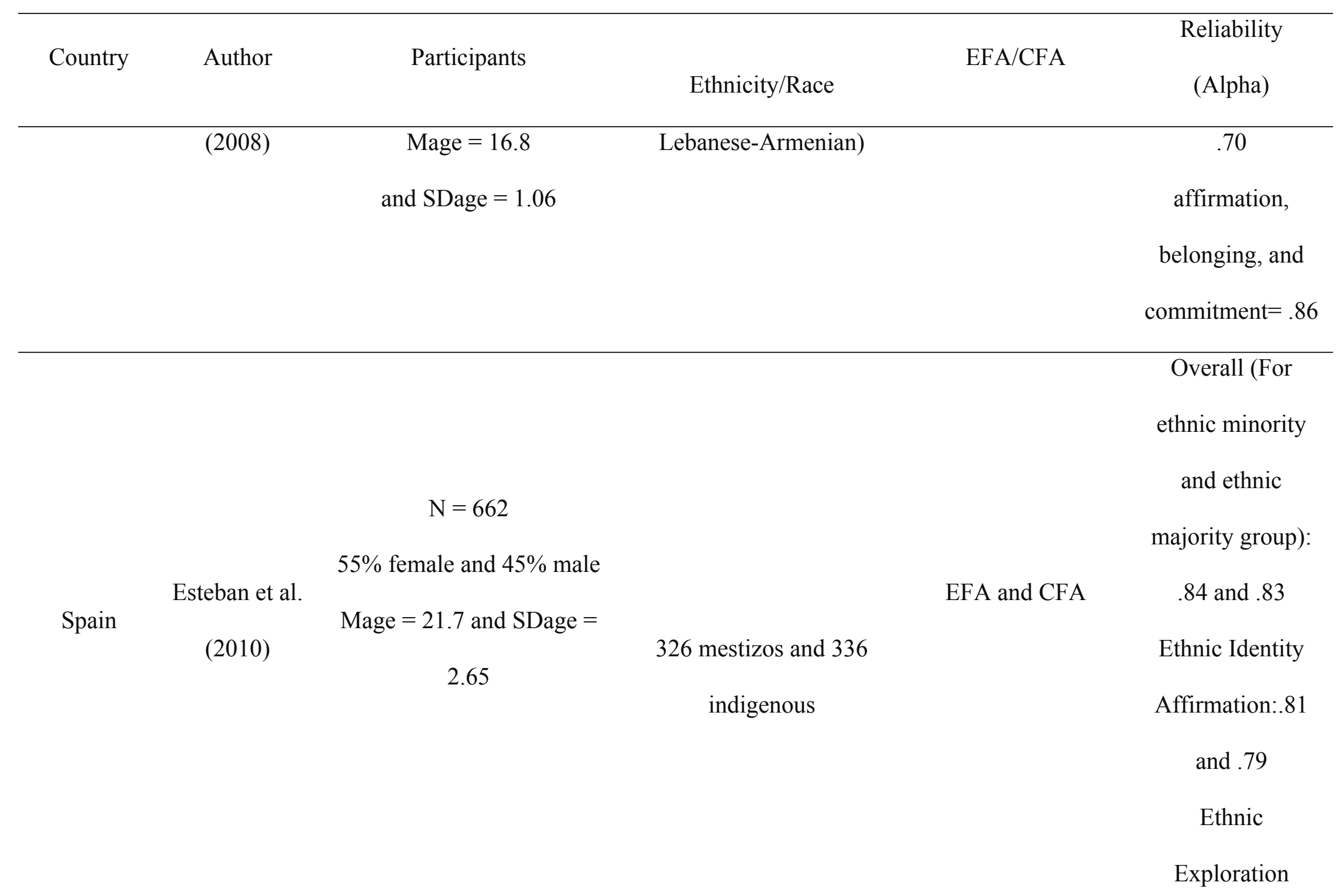




\begin{tabular}{cccc}
\hline Country & Puthor & Reliability \\
& & Ethnicity/Race & EFA/CFA \\
\hline
\end{tabular}

subscale: .76 and

\begin{tabular}{|c|c|c|c|c|c|}
\hline \multirow{5}{*}{ USA } & & $\mathrm{N}=106$ & Bicultural with a slight & \multirow{5}{*}{ CFA } & \multirow{5}{*}{.99} \\
\hline & Burrow- & $91.5 \%$ male & Anglo orientation & & \\
\hline & Sanchez & Mage $=15.5$ & $(44.3 \%)$ or balanced & & \\
\hline & (2014) & and SDage $=1.3$ & bicultural to Mexican & & \\
\hline & & & oriented $(42.9 \%)$ & & \\
\hline \multirow{7}{*}{ USA } & & & Black $(8.3 \%)$ White & \multirow{7}{*}{ CFA } & \\
\hline & & $\mathrm{N}=9,107$ & & & \\
\hline & & & $(60.9 \%)$ Asian (13.7\%) & & \\
\hline & Yap et al. & $72.8 \%$ female & & & \\
\hline & $(2016)$ & Mage $=20.31$ and SDage $=$ & Hispanic (14.8\%) & & \\
\hline & \multirow{2}{*}{\multicolumn{2}{|c|}{3.38}} & Middle Eastern (1.3\%) & & \\
\hline & & & Colored-South & & \\
\hline
\end{tabular}




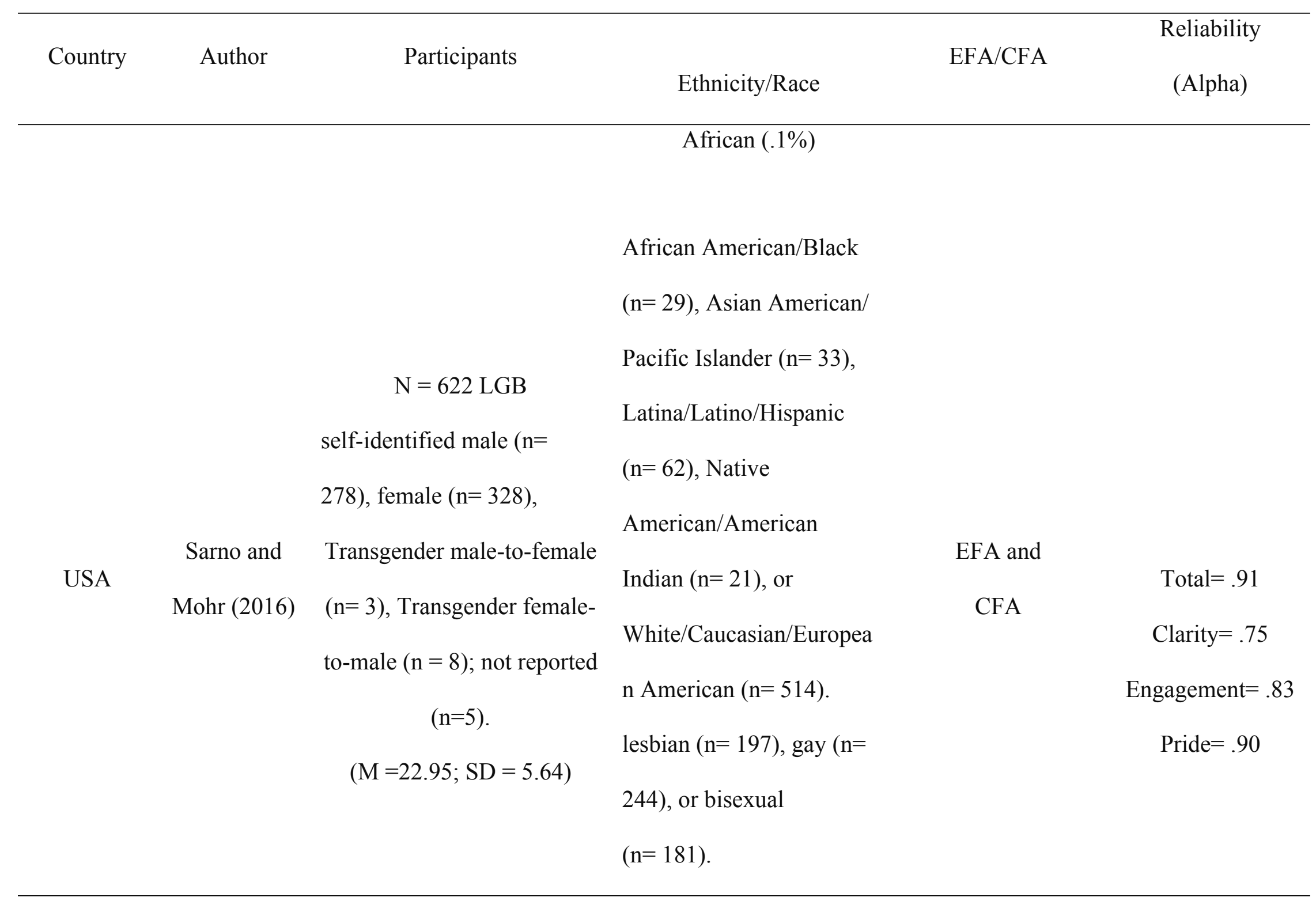




\section{Table 2 (on next page)}

Parameter estimates and goodness-of-fit indexes for CFA of the MEIM

Notes: all parameter estimates were significant at $\mathrm{p}<0.01=* *, Z=Z$ score for tests of univariate normality, P.ET = Parameter estimation for the two-factor oblique model fo total group, and correlated errors, P.Em = Parameter estimation for the two-factor oblique model for male, and correlated errors, P.Ef = Parameter estimation for the two-factor oblique model and correlated errors for female, $\mathrm{M} 1=$ one-factor general model, $\mathrm{M} 2=$ two-factor orthogonal model, M3 = two-factor oblique model, $\mathrm{M3a}=$ two-factor oblique model and correlated errors, $\mathrm{Mb}=$ baseline model for boys with diagonal error covariance, $\mathrm{Mc}=$ model with pattern of factor loadings held invariant, $\mathrm{Mm}=$ baseline model for boys with diagonal error covariance, $\mathrm{Mf}=$ baseline model for girls with diagonal error covariance, $\mathrm{Mvc}=$ model with all factor variances and covariances held invariant, $\mathrm{Mvar}_{-} \mathrm{co}=$ model with variance of commitment held invariant, Mvar_ex= model with variance of exploration held invariant, Mco_var= model with covariance of commitment with exploration held invariant, $\mathrm{Cl}=$ confidence interval, $\mathrm{ECVI}=$ expected cross-validation index, NNFI = non-normed fit index, RMSEA = root mean square error of approximation, $\mathrm{CFI}=$ confirmatory fit index, GFI = goodness of fit index. 
1 Table 2

2 Parameter estimates and goodness-of-fit indexes for CFA of the MEIM

\begin{tabular}{|c|c|c|c|}
\hline Items & Z & P.E $\mathrm{E}_{\mathrm{T}}$ & P. $E_{m}\left(P . E_{f}\right)$ \\
\hline \multicolumn{4}{|l|}{ commitment } \\
\hline 3- I have a clear sense of my ethnic background and what it means for me. & -1.29 & $.70^{* *}$ & $.70^{* *}\left(.70^{* *}\right)$ \\
\hline 5- I am happy that I am a member of the group I belong to. & -4.04 & $.81^{* *}$ & $.86^{* *}\left(.73^{* *}\right)$ \\
\hline 6- I have a strong sense of belonging to my own ethnic group. & -3.26 & $.89^{* *}$ & $.76^{* *}\left(.80^{* *}\right)$ \\
\hline 7- I understand pretty well what my ethnic group membership means to me. & -1.48 & $.82^{* *}$ & $.86^{* *}\left(.77^{* *}\right)$ \\
\hline 9- I have a lot of pride in my ethnic group. & -4.39 & $.85^{* *}$ & $.90^{* *}\left(.81^{* *}\right)$ \\
\hline 11- I feel a strong attachment towards my own ethnic group. & -2.64 & $.89^{* *}$ & $.95^{* *}\left(.83^{* *}\right)$ \\
\hline 12- I feel good about my cultural or ethnic background. & -3.17 & $.77^{* *}$ & $.89^{* *}\left(.67^{* *}\right)$ \\
\hline \multicolumn{4}{|l|}{ exploration } \\
\hline $\begin{array}{l}\text { 1- I have spent time trying to find out more about my ethnic group, such as its } \\
\text { history... }\end{array}$ & -0.76 & $.63^{* *}$ & $.64^{* *}\left(.64^{* *}\right)$ \\
\hline $\begin{array}{l}\text { 2- I am active in organizations or social groups that include mostly members } \\
\text { of my own ethnic group. }\end{array}$ & 1.16 & $.55^{* *}$ & $.62^{* *}\left(.50^{* *}\right)$ \\
\hline $\begin{array}{l}\text { 4- I think a lot about how my life will be affected by my ethnic group } \\
\text { membership. }\end{array}$ & -0.13 & $.58^{* *}$ & $.64^{* *}\left(.50^{* *}\right)$ \\
\hline $\begin{array}{l}\text { 8- In order to learn more about my ethnic background, I have often talked to } \\
\text { other people about my ethnic group. }\end{array}$ & -1.11 & $.79^{* *}$ & $.76^{* *}\left(.84^{* *}\right)$ \\
\hline 10- I participate in cultural practices of my own group, such as special food, & -2.42 & $.75^{* *}$ & $.74^{* *}\left(.78^{* *}\right)$ \\
\hline
\end{tabular}




\begin{tabular}{|c|c|c|c|c|c|c|c|}
\hline \multicolumn{6}{|c|}{ music, or customs. } & \multirow[b]{2}{*}{ ECVI } & \multirow[b]{2}{*}{$\Delta \chi^{2}$} \\
\hline Model & NNFI & RMSEA & CFI & $\chi^{2}(\mathrm{df})$ & GFI & & \\
\hline $\mathrm{M}_{1}$ & .65 & $.087(.076-.099)$ & .71 & $229.69(54)$ & .84 & .65 & - \\
\hline $\mathrm{M}_{2}$ & .28 & $.124(.11-.135)$ & .42 & $407.06(54)$ & .72 & 1.07 & $229.54^{* *}$ \\
\hline $\mathrm{M}_{3}$ & .69 & $.082(.071-.094)$ & .75 & $205.99(53)$ & .85 & .60 & $201.07^{* *}$ \\
\hline $\mathrm{M}_{3 \mathrm{a}}$ & .88 & $.053(.039-.067)$ & .90 & $107.62(49)$ & .92 & .39 & $98.37^{* *}$ \\
\hline $\mathrm{M}_{\mathrm{b}}$ & .91 & $.051(.34-.066)$ & .93 & $151.98(98)$ & .97 & .63 & - \\
\hline $\mathrm{M}_{\mathrm{c}}$ & .90 & .054(.039-.069) & .92 & 177.17(109) & .96 & .64 & $25.19^{* *}$ \\
\hline $\mathrm{M}_{\mathrm{m}}$ & .87 & $.056(.035-.076)$ & .91 & $84.51(49)$ & .94 & .61 & $67.47^{* *}$ \\
\hline $\mathrm{M}_{\mathrm{f}}$ & .94 & $.044(.0095-.069)$ & .93 & $67.47(49)$ & .96 & .65 & $84.51^{* *}$ \\
\hline $\mathrm{M}_{\mathrm{vc}}$ & .90 & $.054(.039-.068)$ & .91 & $181.48(112)$ & .96 & .64 & - \\
\hline $\mathrm{M}_{\mathrm{var} \_\mathrm{co}}$ & .89 & $.055(.040-.069)$ & .91 & $180.50(110)$ & .96 & .64 & .98 \\
\hline $\mathrm{M}_{\mathrm{var} \_\mathrm{ex}}$ & .89 & $.055(.040-.069)$ & .91 & $181.39(111)$ & .96 & .64 & .09 \\
\hline $\mathrm{M}_{\mathrm{co} \_ \text {var }}$ & .90 & $.054(.040-.069)$ & .91 & $180.73(111)$ & .96 & .64 & .75 \\
\hline
\end{tabular}

3 Notes: all parameter estimates were significant at $\mathrm{p}<0.01=* *, \bar{Z}=\mathrm{Z}$ score for

4 tests of univariate normality, P. $\mathrm{E}_{\mathrm{T}}=$ Parameter estimation for the two-factor

5 oblique model fo total group, and correlated errors, P. $\mathrm{E}_{\mathrm{m}}=$ Parameter estimation

6 for the two-factor oblique model for male, and correlated errors, P. $E_{\mathrm{f}}=$ Parameter

7 estimation for the two-factor oblique model and correlated errors for female, $\mathrm{M}_{1=}$

8 one-factor general model, $\mathrm{M}_{2}=$ two-factor orthogonal model, $\mathrm{M}_{3}=$ two-factor 
9 oblique model, $\mathrm{M}_{3 \mathrm{a}=}$ two-factor oblique model and correlated errors, $\mathrm{M}_{\mathrm{b}=}$ baseline

10 model for boys with diagonal error covariance, $M_{c}=$ model with pattern of factor

11 loadings held invariant, $\mathrm{M}_{\mathrm{m}}=$ baseline model for boys with diagonal error

12 covariance, $\mathrm{M}_{\mathrm{f}}=$ baseline model for girls with diagonal error covariance, $\mathrm{M}_{\mathrm{vc}}=$

13 model with all factor variances and covariances held invariant, $\mathrm{M}_{\mathrm{var}-\mathrm{co}=}$ model with

14 variance of commitment held invariant, $\mathrm{M}_{\mathrm{var}-\mathrm{ex}=}$ model with variance of exploration

15 held invariant, $\mathrm{M}_{\mathrm{co} \_ \text {var }}$ model with covariance of commitment with exploration

16 held invariant, $\mathrm{CI}=$ confidence interval, $\mathrm{ECVI}=$ expected cross-validation index,

$17 \mathrm{NNFI}=$ non-normed fit index, RMSEA = root mean square error of approximation,

$18 \mathrm{CFI}=$ confirmatory fit index, GFI $=$ goodness of fit index. 


\section{Table 3 (on next page)}

Internal Consistency Coefficients, Mean Inter-Item Correlation, Means, and Standard Deviations for males, and females

Note: $\mathrm{p}<.01=* *, \mathrm{MEIM}=$ Multigroup Ethnic Identity Measure, Values for females are inside the parenthesis. 


\section{$1 \quad$ Table 3}

2 Internal Consistency Coefficients, Mean Inter-Item Correlation, Means, and Standard

3 Deviations for males, and females

\begin{tabular}{lllll}
\hline Multigroup ethnic identity & $\alpha$ & Correlation & $\mathrm{M}$ & SD \\
\hline Commitment & $.91(.88)$ & $.59(.51)$ & $22.12(21.02)$ & $4.61(4.34)$ \\
Exploration & $.78(.75)$ & $.41(.38)$ & $13.68(12.75)$ & $3.15(3.27)$ \\
MEIM & $.92(.90)$ & $.49(.42)$ & $35.76(33.81)$ & $7.29(7.03)$ \\
& & & & \\
\hline
\end{tabular}

4 Note. $\mathrm{p}<.01=* *$, MEIM $=$ Multigroup Ethnic Identity Measure, Values for females are inside 5 the parenthesis.

6 


\section{Table 4 (on next page)}

Mean and standard deviation of time 1 and 2 and test-retest reliability of MEIM and subscales

Note: intra-class correlation coefficient, all $p$ values $<.01$ 


\section{Table 4}

2 Mean and standard deviation of time 1 and 2 and test-retest reliability of MEIM and subscales

\begin{tabular}{llllll}
\hline Measures & Time1 & \multicolumn{3}{c}{ Time 2 } & r \\
\cline { 2 - 5 } & & M & SD & M & SD \\
\cline { 2 - 5 } commitment & 23.15 & 5.12 & 23.9 & 4.89 & .91 \\
exploration & 13.89 & 3.2 & 14.45 & 3.4 & .82 \\
MEIM (Total Score) & & & & & \\
& 35.89 & 6.15 & 36.15 & 7.01 & .86 \\
\hline
\end{tabular}




\section{Table 5 (on next page)}

Correlations between the Ethnic identity and its subscales and subjective well-being including positive affect, negative affect, and life satisfaction $(n=426)$

Note:** $\mathrm{P}<.01$ (two-tailed) 


\section{Table 5}

2 Correlations between the Ethnic identity and its subscales and subjective well-being including

3 positive affect, negative affect, and life satisfaction $(n=426)$

\begin{tabular}{llll}
\hline Measures & Positive affect & Negative affect & Life satisfaction \\
\hline Ethnic identity & $.28^{* *}$ & $-.29 * *$ & $.31^{* *}$ \\
commitment & $.28^{* *}$ & $-.25^{* *}$ & $.32 * *$ \\
exploration & $.23 * *$ & & $.25^{* *}$ \\
\hline
\end{tabular}

Notes: $* * \mathrm{P}<.01$ (two-tailed) 